\title{
Access is Better than Ask Us
}

\section{Thomas E Catanzaro*}

American College of Healthcare Executive, CEO, Veterinary Consulting International, Australia

*Corresponding author: Catanzaro TE, American College of Healthcare Executive, CEO, Veterinary Consulting International, Australia, Tel: +610416285975; E-mail: DrTomCat@aol.com

\section{Received date: August 08, 2016, Accepted date: August 24, 2016, Published date: August 29, 2016}

Copyright: (C) 2016 Catanzaro TE. This is an open-access article distributed under the terms of the Creative Commons Attribution License, which permits unrestricted use, distribution, and reproduction in any medium, provided the original author and source are credited.

\section{Introduction}

It isn't difficult to understand why some practices have a dwindling number of clients when access is assessed from the client's viewpoint. The only thing a veterinary practice has to "sell" is peace of mind to the client; everything else must be allowed to be "bought" by the client accessing the facility.

\section{The Client Perception}

Whether you agree with the concept or not, the truth is that whatever the client perceives as reality, is reality to that client. An unhappy client will tell eleven other people and each of those will tell five more; a happy client only tells four or five. A neutral client does not help or hinder, and sometimes, they may or may not come back, depending on environmental factors between visits. One of those "environmental factors" is most often the new competition in the area of every practice, whether it be another practice, a pet super store, or a community perception shift.

James Herriott, of All Creatures Great and Small fame, provided a big boost to the public's perception of veterinarians, but that era is over and has been replaced by TV staged "reality" shows about veterinarians. All veterinarians gained equally from the goodwill generated by that best seller series and the subsequent television series, even though most veterinarians don't possess James Herriot's quiet charm or today's "staged reality" stories. Today, veterinarians need to be mindful of how their clients perceive them and the basis for those perceptions. The average client can comfortably evaluate a specific practice by only five parameters: 1) a word-of-mouth recommendation, 2) a caring staff, 3 ) if their pet's condition improves after its encounter with that practice, 4) being served when they feel they need veterinary care and 5) sight, smell, and sound of the practice encounter. A veterinarian's ability as a diagnostician or adeptness as a surgeon are factors that most clients are unable to evaluate, therefore, to please your clients it isn't enough to be a skilled veterinarian.

Consider the client who calls and is put on hold and forgotten for over 30 seconds (a lifetime on a silent phone). Some practices put telephone messaging on the hold line, but the extended hold time is often perceived as a marketing ploy, especially if the messages have not been tailored, so the client hangs up and goes to the next closest practice willing to talk to them. Your telephone is the primary link between stressed and needy clients and your practice. When was the last time you asked the phone company to do a "busy signal" count on your lines? Most every phone company will provide this service, they will tell you by half-hour increments, when the phones were busy (clients heard a busy signal) and at what rate.

What about the client who needs to drop off the pet for medical care, surgery, vaccinations, or just day care observation on the way to work? Most practices will "accommodate" a client's need if asked, but how many make it a standard client service and OFFER it to every client? What about the client who needs to pick up the pet after "normal hours?" How comfortable does your practice make the client feel when this is required? Is it OFFERED to each client, or is it again only upon request and the client is made to feel the practice is really going out of its way to meet the needs of that client? This perception is especially true when practices close the doors at 5 or 5:30 p.m. on weekdays. In many suburban areas, the family is not at home until after 6 p.m., and only then can they go get their pet. Anticipating the client's access needs and changing the attitude, "We do it if they ask us," is the way to make clients feel important. Clients who perceive they are important when they leave your practice are the ones who will come back with the next question.

The two- to three-hour lunch hour is the other "perception pit" many practices fall into on a regular basis. The "Doc" says, "No appointments after 11:30 this morning, I have a lunch date." The staff tells clients, "Doc's out to lunch and can't see you for three hours." The stressed client calls the next practice on the list. The alternative reply is seldom provided in the practice's training expectations, "The doctor is engaged with another case, but we can admit "Fluffy" anytime this morning, examine him/her over the lunch period, and then make an appointment for you to talk to Doctor "X" mid-afternoon, by phone or in person; which would you prefer?" The client calls because they want help, not a delay!

\section{Two Yes Answers}

When a client calls, a "yes" answer is needed. The "no" word, which is often stated as "can't" or "it's not our policy," is not the way to retain and nurture clients. Why does the new pet superstore get clients? Low prices and easy access attracts the frustrated pet owner. Oh yes, they still will take "Fluffy" to their "regular vet" for sick cases, but the new "shoot and scoot" veterinary clinic is s-o-o-o much easier and cheaper. The key is to offer two "yes" alternatives to every client question or need, never just a yes-no combination.

The ten-minute blocks appointment log (standard appointment is two slots, new clients, eyes, two pets and other exceptions would get three slots), has "E" blocks mid-morning and mid-afternoon in each column, but out of sync (e.g., two consult rooms per doctor, so scheduling needs to over-lap first ten in one room to last ten in the other). These "E" slots re simply lightly shaded lines, a single ten minute slot, kept open until the day of the appointment page, where the emergency can access the hospital. It should only take a trained team ten minutes to process an emergency case for inpatient care. By policy, an "emergency" should have only ONE simple definition in any healthcare facility, and that is "AS PERCEIVED BY THE CLIENT!" If they call, they want access, a "yes" answer to their pet's perceived needs, 
not your equivalent to the old "take two aspirin and call me in the morning" attitude which has made physicians infamous (and unappreciated). If your practice philosophy is to assess an "emergency fee" or "day inpatient fee" whenever a patient accesses the hospital via an emergency slot, so be it; you know the perceptions of your clients better than most.

The ability to buy is an American's right; the experience of being sold is a "buyer beware" atmosphere. Americans love to buy, but they react negatively when they feel they were sold something other than what they perceived they needed. Don't oversell the encounter. Address the client's perceived needs of the pet first; the client's concern is why they came to you! When the "subtle" signs of other problems are found during the examination, the "two yes's" approach is, "We can deal with this other problem at the recheck (which spreads out the cost and ticket shock), or we could treat the problem today if you wish to leave Fluffy with us until later this afternoon (thereby not delaying the next client and their expectations), the choice is yours; which would you prefer today?".

\section{The Three Whys}

We accept that the basics of WHAT, WHY, WHO, HOW and WHEN, yet that is not enough to get complete buy-in from the client or even your team. They want to know: "If I behave in this new way, how will this practice help fulfil my values-driven need for purposeful, worthwhile patient care plan that makes the difference in the lives of the patient (and/or client)? (NOTE: most all staff members, veterinarians included, are in this profession because it is a calling, not a source of independent wealth.) Show me how this new program/ practice will help me achieve that personal ambition and I am hooked."

Answering three specific WHYs can improve a practice's success and create a more transparent communication with clients as well as the practice staff, which leads to better client communications, which leads to better care for your patients and higher levels of pride within the staff (Pride is perceived by clients as quality, which bonds them to the practice, and allows them to better accept the costs of higher quality veterinary healthcare delivery. But to do this right, facilitators have found there are a few additional tips that are helpful; there are really three WHYs in any compelling communication:

- The why that satisfies our rational side. This is the WHY of the mind, and it is the realm of published data - most veterinarians learned to lead with this message.

- The why that satisfies our emotional side. This is the WHY of the heart, a feeling that leverages the power of a compelling story. Few veterinarians have had formal training on this one.

- The why that satisfies the person's individual needs. This is the why for yourself, as a person, and the sample size is YOUR life experiences. This is the reason most join this profession, yet is seldom integrated into the buy-in process for the staff.

The leader that crafts a message that addresses all three whys will see a dramatic increase in the likelihood that the message will be successfully adopted.

\section{Access}

Watch the trends in your community. Why do the clients try the new veterinarian or the new pet super store? Satisfied clients seldom practice hop, but clients do seek alternatives when they are not offered at their current veterinary healthcare facility. Don't look for excuses and don't try to blame someone else; just seek ways to adjust your practice and serve your clients better. In the process, learn new ways to cope while addressing the client's perceptions of value and caring!

If you argue that the practice cannot compete with the pet food prices at the local super store, it means clients do not understand the nutritional needs when using a premium diet, and they over-feed like they learned with grocery store pet food. Premium prescription diets for adult maintenance (e.g., Hills), or it could be Royal Canin for teeth (triple approach), you may prefer the IAMS kennel plan (with ample free samples), or maybe the newest ProPlan promotional, or maybe another prescription diet of your preference. Prescription diets usually have some net, while maintenance diets have client convenience; healthcare has the greatest net!

If you argue that a nurse technician must come in an hour early or stay to an hour late to meet a client's need, remember that the extra hour costs you about $\$ 10$ to $\$ 20$. One additional $\$ 50$ client transaction is worth more than that, in fact, ONLY one additional transaction each weekday for a month is an extra $\$ 12,000$ per year. If you determine whether your existing "wellness" nurse technician is a morning or evening person, and hire a contrasting outpatient nurse technician, then the split-shift nurse technicians are brighter and happier when they work their preferred shift. Happy and caring nurse technicians can change the perceptions of stressed clients just by being there for them.

The reality of success is based on client perceptions, not in logic or professional reason. Isoflurane is not an "expensive" gas, it is "the safest gas for your pet." Lyme vaccine is not a "new vaccine," it is "finally we have a protection for pets exposed to ticks." Dental prophys do not correct gingivitis, they "reduce bad breath." The secret to improving access is to wear the client's shoes, after you remove yours. Don't take your bias into their minds. Remember the healthcare adage: No one really cares how much you know until they know how much you care. Access is a perception! 